\title{
Estimation of Aboveground Biomass and Carbon Stock of Bacolod Protected Landscape and Seascape Using LiDAR Data and GIS
}

\author{
Fejaycris O. Pillodar ${ }^{1}$, Danilo C. Mero ${ }^{2}$, Daniel S. Mostrales ${ }^{1}$, Shara Grace C. Astillero ${ }^{1}$, \\ and Ma. Teresa T. Ignacio ${ }^{1}$
}

\begin{abstract}
By quantifying mangrove extent, aboveground biomass (AGB) and carbon stock (CS) are of great importance for addressing climate change adaptation and mitigation. This study aims to estimate the AGB and CS of mangroves along the coastline of Bacolod, Lanao del Norte, Philippines with the use of Light Detection and Ranging (LiDAR) technology. Field data validation were conducted from a two separated $20 \mathrm{~m} \times 20 \mathrm{~m}$ quadrant inside the study area. Investigated field values such as diameter at breast height $(\mathrm{DBH})$ and total height were used in allometric equations. Furthermore, 17 LiDAR derived parameters were used upon generating the composite bands which is also used in estimating AGB and CS of mangroves. Different models like digital terrain model (DTM), canopy height model (CHM) and canopy cover model (CCM) were made to obtain more accurate values of the AGB and CS. Results showed that the AGB and CS of Bacolod Protected Landscape and Seascape has a mean of $3,654.75 \mathrm{~kg} / 20 \mathrm{mx} 20 \mathrm{~m}$ and $1,717.73 \mathrm{~kg} / 20 \mathrm{mx} 20 \mathrm{~m}$ respectively. The distribution of AGB and CS were mapped from the results.
\end{abstract}

Keywords-Aboveground biomass, carbon stock, LiDAR, mangroves.

\section{INTRODUCTION}

Mangrove forests are very important coastal means, which are vibrant to our socio-economic development. A huge number of the human population are living in the coastal area, and most communities depend on local resources for their livelihood. Mangroves are sources of exceedingly valued commercial products and fishery resources and also as sites for developing a growing eco-tourism [1].

\section{A. Mangroves in the Philippines}

The Philippines' mangrove forests offer abundant ecosystem goods and services to coastal communities. Mangroves are conventionally used for firewood, charcoal, alcohol, medicines, and thatching used for construction [2]-

This work was supported by the Phil-LiDAR 2 Program Department of Science and Technology (DOST).

Fejaycris Pillodar, Daniel Mostrales, Shara Grace Astillero, and Ma. Teresa Ignacio are with the Phil-LiDAR 2, Mindanao State University - Iligan Institute of Technology, Tibanga Highway, Iligan City 9200 Philippines

Danilo Mero was with Mindanao State University - Main Campus, Marawi City 9700 Philippines. He is also a project staff of MSU-IIT Phil-LiDAR 2, Iligan City 9200 Philippines
[3]. In storm surges, it reduces the height and energy of the wind and swell waves passing through them, reducing their ability to erode sediments and to cause damage to structures such as dikes and sea walls [4]. In addition, mangroves have also highlighted in discussions on global climate change, in particular with reference to Reduced Emissions from Forest Degradation and Deforestation Plus (REDD+) [5], [6], [7].

\section{B. Mangrove degradation}

In spite of its important role in coastal area undercurrents, mangrove ecosystems are facing pervasive destruction resulting from natural hazards and human interference. Be it on the global, regional or national scale, the circumstances are the same; there is a significant decrease in the world's total mangrove area over time [8], [9], [10].

\section{Importance of mangrove biomass and carbon stock}

Mangrove productivity is a measure of the ecological value of a mangrove ecosystem. High productivity values equate to a larger number and a more diverse array of organisms that can be supported within a particular ecosystem. Productivity is measured as the amount of living material (i.e. stem, branches, leaf, and roots) produced by the mangrove community over time. It is often measured through leaf litter and biomass production. Biomass component consists of aboveground and below-ground biomass (BGB) of mangroves. However, owing to the difficulty of obtaining samples for BGB production AGB is the often measured [11].

Reliable estimates of biomass are essential for estimating total net primary production in ecological studies, assessing the yield of commercial products from mangroves, providing a baseline of CS that relate to the issue of global climate change [12]. However, recent emerging airborne LiDAR technology provides an ideal tool to conduct a non-destructive AGB and CS extents since the tree height data can be derived directly from LiDAR measurements. Airborne LiDAR systems are capable of measuring objects on the earth surface with a horizontal resolution of several meters and centimeter vertical accuracy [13]. At the international level, there is numerous available information regarding mangrove biomass estimates but locally, we have very limited studies done. It is, 
therefore, necessary to conduct studies that will furnish data in biomass production of different forest ecosystems such as mangrove forests.

In particular, a very high-resolution LiDAR-derived data were utilized to produce a map of the estimated AGB and CS as well as the other important data such as CHM, DTM and CCM.

\section{II.METHODOLOGY}

\section{A. Study area}

The Bacolod Protected Landscape and Seascape (formerly named as Liangan River Mangrove Reserve) was located along the coastline of Bacolod, Lanao del Norte. Communities rely on their livelihood commonly in this type of ecosystem. By using object-based image analysis (OBIA) with its assigned spectra, mangroves are extracted from a high-resolution image or orthophoto (Fig. 1).

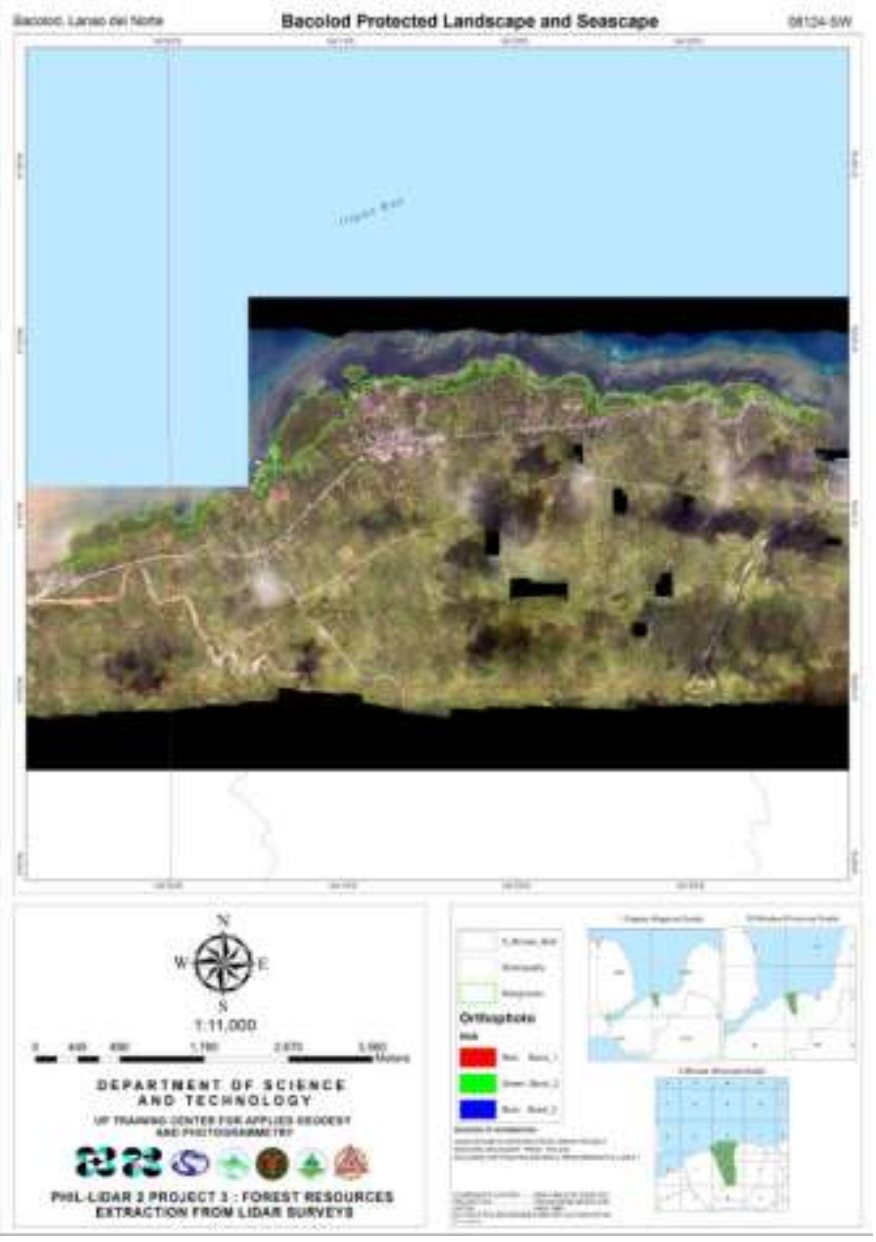

Fig. 1 Bacolod Protected Landscape and Seascape

\section{B. Workflow and target parameters}

Before the batch files are given, every forest types were pre-validated by the University of the Philippines Diliman Forest Resource Extraction from LiDAR Surveys (UPD-
FRExLS) team to obtain numerical datasets and spectra of each forest types and will be used as an input to the endmember collection when processing the spectral angle mapper. Classified LAS, orthophotos, and metadata are produced from LiDAR data acquisition (Fig. 2). This three raw datasets are used for the whole processing.

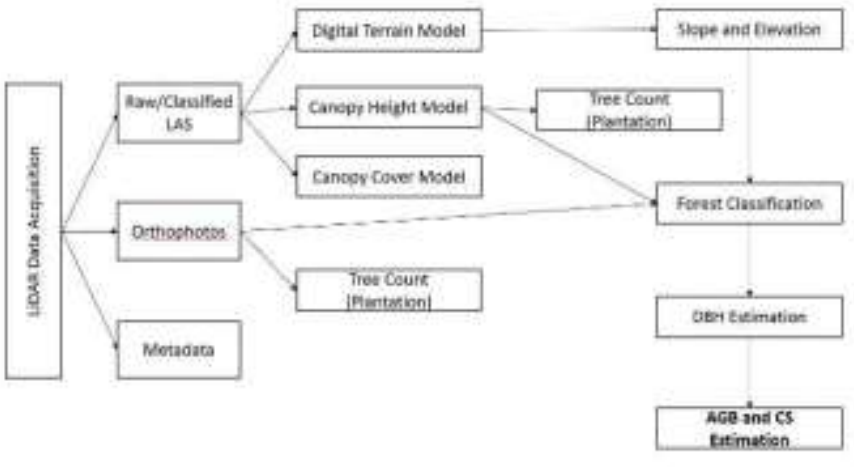

Fig. 2 FRExLS workflow for AGB and CS estimation

\section{LiDAR data and derivation}

LiDAR point cloud data of Bacolod Protected Landscape and Seascape (BPLS) was acquired and pre-processed by the Disaster Risk and Exposure Assessment for Mitigation (DREAM) Project [14]. The LiDAR point cloud has an average point density of 2 points $/ \mathrm{m}^{2}$ and an average resolution of 1 meter (Fig. 3).

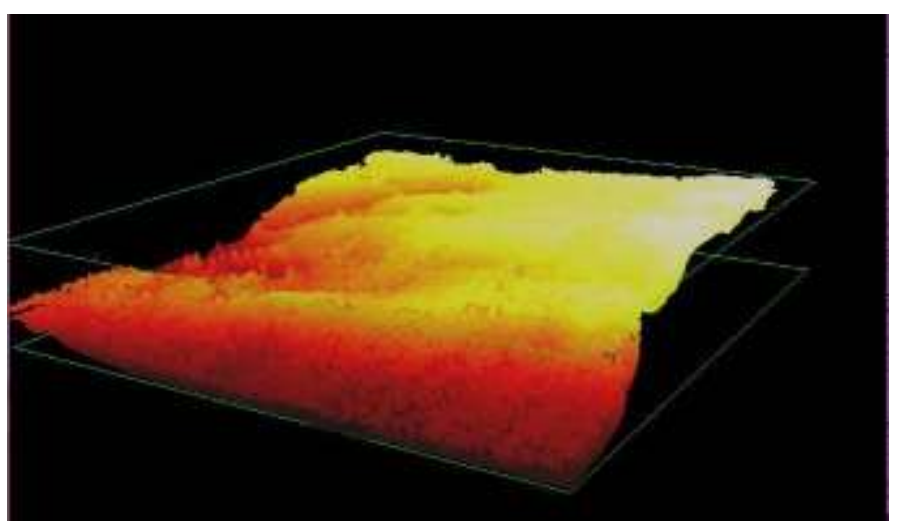

Fig. 3 A 1-meter resolution of LiDAR point cloud of BPLS preprocessed from DREAM Project

\section{CHM, DTM, and CCM}

The FRExLS component has given batch files programmed by the UPD-FRExLS team to be used in LiDAR processing.

CHM (Fig. 5) are commonly used for extracting relevant forest information. Often irregular height differences which also called data pits are existing in the CHM. These pits typically appear when the first Lidar return is far below the canopy which tends to happen for two explanations. The first cause is that a laser beam deeply breaches through the branches and the foliage before producing the first return [15]. The second reason is multiple laser beams - probably from different flight lines that produce their first return in 
close horizontal juxtaposition but with a great height difference because they "see" the canopy or the ground from different angles [16]. From normalizing the height of the LiDAR data, partial CHMxx rasters is computed by all returns below a certain height (meters) threshold (max $\mathrm{z}$ value) where $\mathrm{xx}$ is the threshold: $0-\max \mathrm{z}, 2-\max \mathrm{z}$, and $n$ $-\max z$, where $n$ is increased by 5 (Fig. 4) [17].

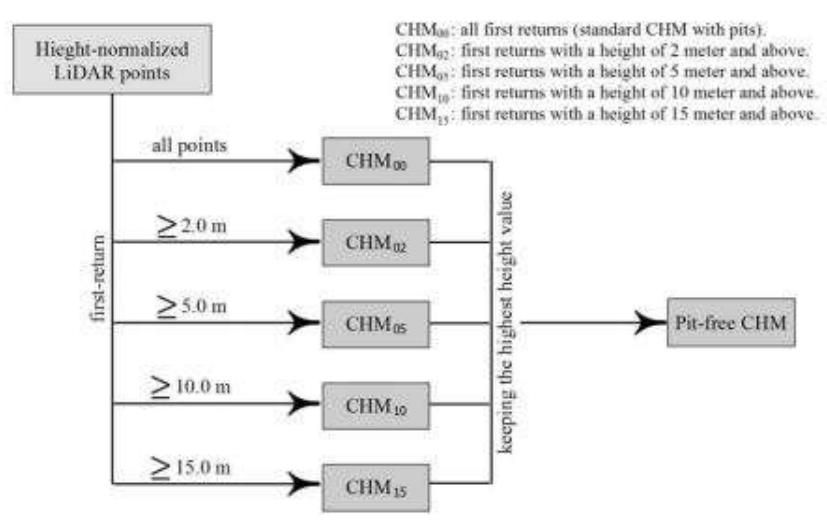

Fig. 4 A simple diagram of a pit-free algorithm's workflow.

Another output produced from the same script were DTM that illustrated the bare elevation of a surface (Fig. 5) and CCM which displayed the percentage canopy cover of a certain vegetation.

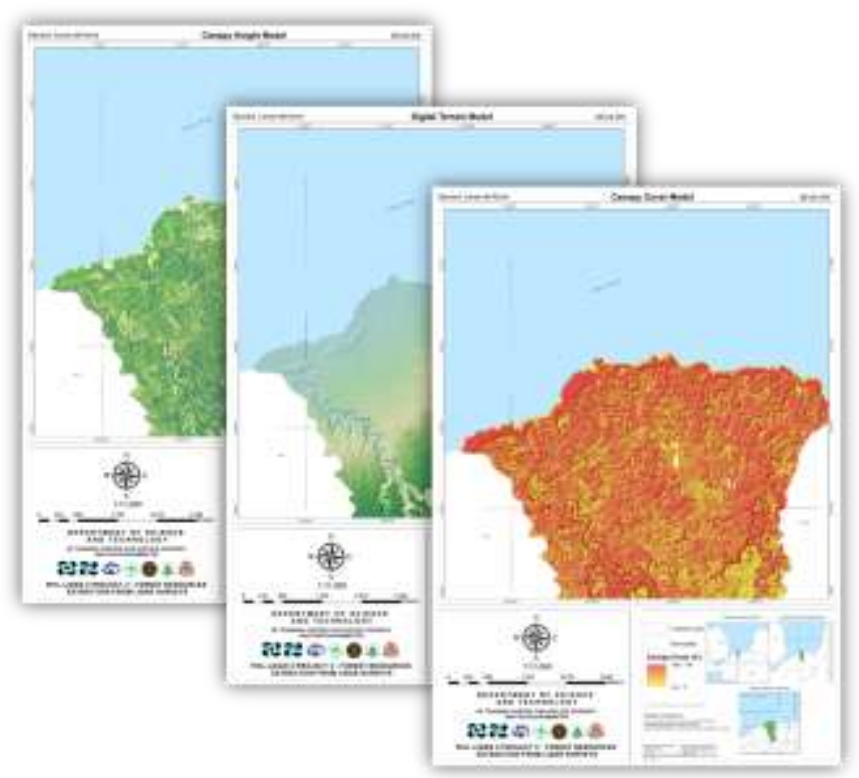

Fig. 5 CHM (top), DTM (middle), and CCM (bottom) of Bacolod, Lanao del Norte

\section{E. LiDAR parameters}

Canopy metrics (Fig. 6) are the measured percentage of all first returns as well as the number of points inside a $5 \mathrm{~m}^{2}$ area. Likewise, height and intensity metrics determines the height intensity of point clouds which are present in every $5 \mathrm{~m}^{2}$. While the percentiles and bicentiles are the height values or intensity given in the nth percentile points and the percentage of points given the $n t h \%$ of the maximum height. All of these parameters were produced by using LAStools and ArcGIS softwares. These parameters are then used to estimate the diameter at breast height $(\mathrm{DBH})$ of the mangrove forest.

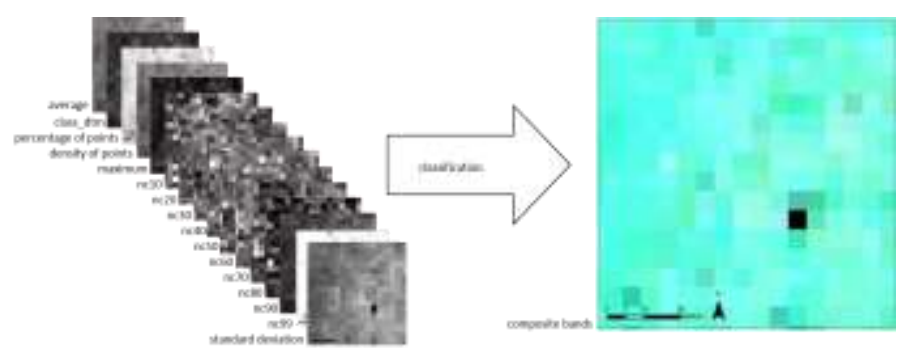

Fig. 6 LiDAR parameters (left) are combined to generate composite bands (right) which is used to reclassify the identified mangroves from other types of forests

\section{RESULTS}

By means of spectral angle mapper in ENVI software, composite bands (Fig. 6) are used to reclassify the mangroves in the area with wavelength values of 8.225000, 98.075000, $96.675000,11.400000,2.600000,1.025000,1.550000$, $2.450000,6.175000,9.575000,13.875000,19.125000$, 25.050000, 17.525000, 75.600000, 2.025000, and 50.175000 are then classified as natural mangroves. With the convention of majority analysis method, kernel size is adjusted to 5 . Results concluded that natural mangroves are dominant in the area (Fig. 7). By converting the data into a vector or a shapefile, this data are being used as a boundary or an extent in calculating the aboveground biomass and carbon stock.

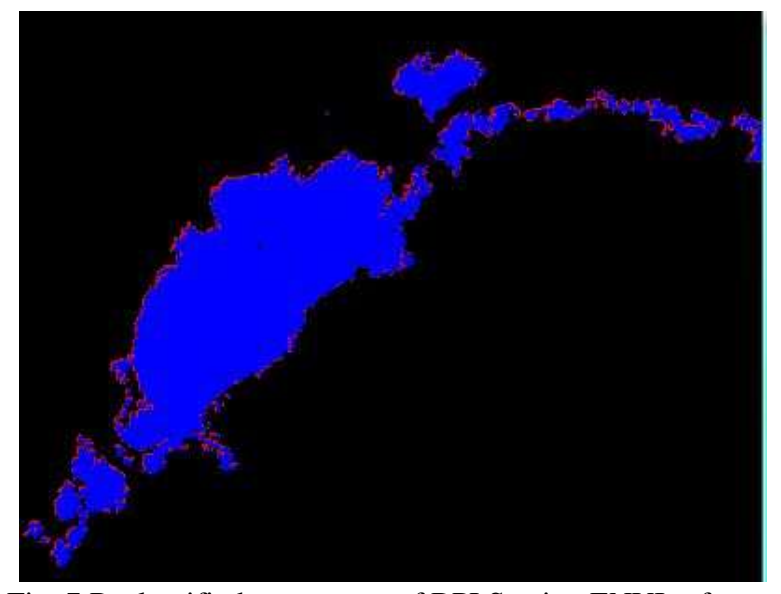

Fig. 7 Reclassified mangroves of BPLS using ENVI software

\section{A. Field validation and accuracy assessment}

Two plots were selected in the area to be represented as dense and sparse and were investigated. Actual mensuration of $\mathrm{DBH}$ and a total height of each individual species are identified. Each plot is measured $20 \mathrm{~m} \times 20 \mathrm{~m}$ and in each first point were averaged by the GPS from one up to one and a half hours. With this primary data allometric equations for mangrove biomass include: 


$$
W a g b=0.251 \rho D^{\wedge} 2.46
$$

Waypoint 1 was placed in an open canopy (Fig. 8) in order to get a slighter error due to disturbances such as clouds and weather condition as well.

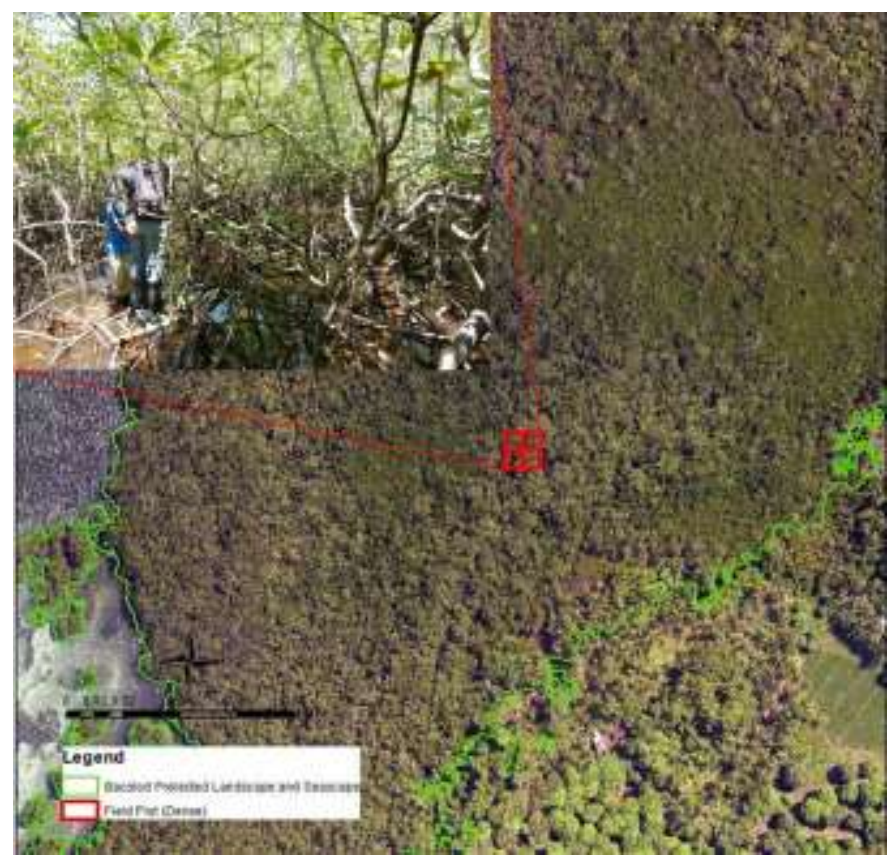

Fig. 8 A senior science research specialist and his assistant placing the first point of the plot

One of the limitations of LiDAR technology is that it cannot directly measure some important features in a forest area. Such that, the AGB and CS can only be measured through indirect measurements. Thus, these parameters (dependent variable) are estimated using regression analysis to derive its relationship to the independent variable (LiDARderived parameters) (Fig. 9).

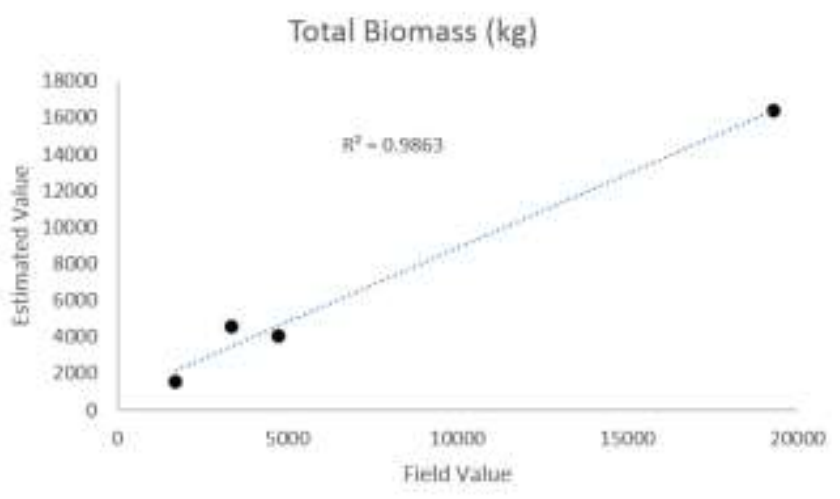

(a)

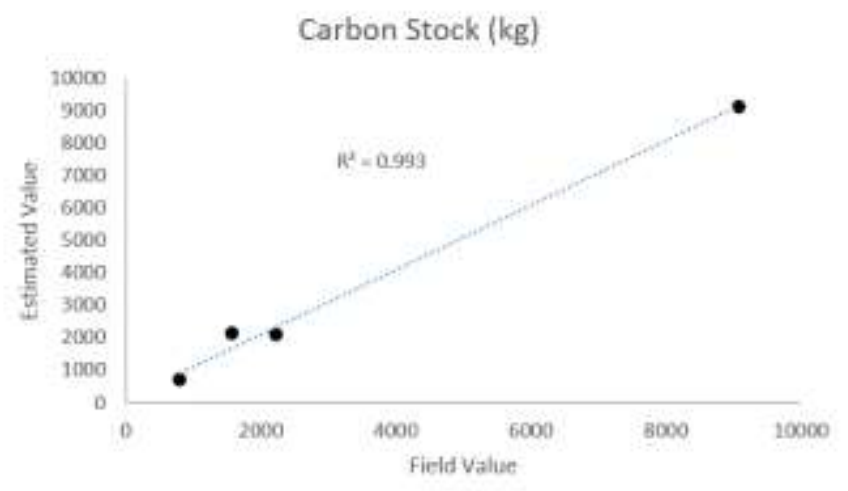

(b)

Fig. 9 Comparison of the estimated values and field values of aboveground biomass $(a)$ and carbon stock $(b)$

\section{CONCLUSION}

Through LiDAR technology, this paper identified and mapped the AGB and CS of Bacolod Protected Landscape and Seascape. It is estimated that AGB of the area has a mean of $3,654.75 \mathrm{~kg} / 20 \mathrm{mx} 20 \mathrm{~m}$ and CS has a mean of $1,717.73$ $\mathrm{kg} / 20 \mathrm{mx} 20 \mathrm{~m}$. Through this technology, areas that are too hard to access are possible to evaluate and can be investigated. The study proves that the Bacolod Protected Landscape and Seascape has a vast biomass potential which can be given a big help from the locals to preserve and can be of big advantage in climate change mitigation.

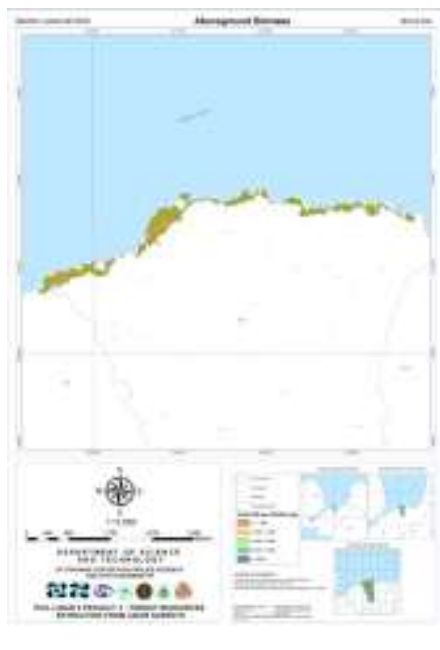

(a)

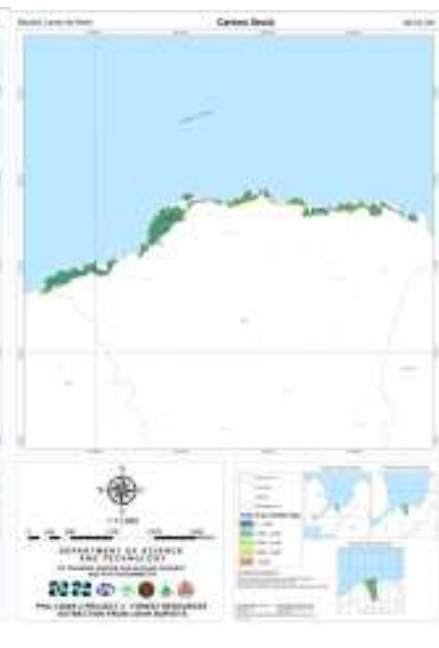

(b)
Fig. 10 Aboveground biomass $(a)$ and carbon stock $(b)$ of Bacolod Protected Landscape and Seascape

\section{ACKNOWLEDGMENT}

Big thanks are given to the Department of Science and Technology (DOST) and Mindanao State University - Iligan Institue of Technology (MSU-IIT) Phil-LiDAR 2 staffs who fully supported to fund the research and helped to realize the project and for the development of this paper. 


\section{REFERENCES}

[1] Kathiresan K., and Bingham B.L., 2001, Biology of mangroves and mangrove ecosystems, Advances in Marine Biology, 40: 81-251 http://dx.doi.org/10.1016/S0065-2881 (01)40003-4.

[2] Brown, W.H.; Fischer, A.F. Philippine Mangrove Swamps; Bureau of Printing: Manila, Philippines, 1918; p. 132.

[3] World Mangrove Atlas; Spalding, M.D., Field, C.D., Eds.; The International Society for Mangrove Ecosystems: Okinawa, Japan, 1997.

[4] Spalding M, McIvor A, Tonneijck FH, Tol S and van Eijk P (2014) Mangroves for coastal defense. Guidelines for coastal managers \& policy makers. Published by Wetlands International and The Nature Conservancy. 42 p.

[5] Lieth, H., Whittaker, R.H., Eds. Primary Production of the Major Vegetation Units of the World. In Primary Productivity of the Biosphere; Springer: Berlin/Heidelberg, Germany, 1975; pp. 305-328.

[6] McNally, R.; McEwin, A.; Holland, T. The Potential for Mangrove Carbon Projects in Vietnam; SNV-Netherlands Development Organisation REDD+ Programme: Ha Noi, Vietnam, 2011.

[7] Kristensen, E.; Bouillon, S.; Dittmar T.; Marchand, C. Organic carbon dynamics in mangrove ecosystems: A review. Aquat. Bot. 2008, 89, 201219.

https://doi.org/10.1016/j.aquabot.2007.12.005

[8] Brown WH and Fischer AF.1918. Philippine Mangrove Swamps. 132 p.

[9] Giesen W, Wulfraat S, Zieren M, \& Scholten L. 2007. Mangrove Handbook for Southeast Asia. Thailand: Dharmasarn Co., Ltd. 769 pp.

[10] Simard M, Zhang K, Rivera-Monroy VH, Ross MS, Ruiz PL, CastañedaMoya E, Twilley RR, \& Rodriguez E. 2006. Mapping Height \& Biomass of Mangrove Forests in Everglades National Park with SRTM Elevation Data. In Photogrammetric Engineering and Remote Sensing. Vol.72, No.3, pp.299-311. https://doi.org/10.14358/PERS.72.3.299

[11] Brown S and Lugo AE.1982. A comparison of structural and functional characteristics of saltwater and freshwater forested wetlands, 109-130 pp. In B. Gopal, R.E. Turner, R.G. Wetzel, \& D.E. Whighams (eds.) Wetlands ecology and management. Proc. 1st Int. Wetlands Conf., New Delhi, India.

[12] AL Codilan, MG Carandang, MM Calderon, and FM Eslava. 2009. Aboveground biomass production of three mangrove species in Real, Quezon Province, Philippines, ISSN 0302-7937, 191-197

[13] Hyyppa, J., H. Hyyppa, P. Litkey, X. Yu, H. Haggren, R. Petri, U. Pyysalo, J. Pitkanen, and M. Maltamo, 2004. Algorithms and methods of airborne laser scanning for forest measurements, Proceedings of the ISPRS Working Group VIII/2 on Laser Scanners for Forest and Landscape Assessment, Freiburg, Germany, XXXVI (8/W2)

[14] UP TCAGP (2015), DREAM LiDAR Data Acquisition and Processing for Iligan City Floodplain, Disaster Risk and Exposure Assessment for Mitigation Program, DOST Grants-in-Aid Program.

[15] Persson, A., Holmgren, J., and Soderman, U., 2002. Detecting and measuring individual trees using an airborne laser scanner. Photogrammetric Engineering and Remote Sensing, 68, 925-932.

[16] Leckie, D., Gougeon, F., Hill, D., Quinn, R., Armstrong, L., and Shreenan, R., 2003. Combined high-density lidar and multispectral imagery for individual tree crown analysis. Canadian Journal of Remote Sensing, 29, 633-649. https://doi.org/10.5589/m03-024

[17] Anahita Khosravipour, Andrew K. Skidmore, Martin Isenburg, Tiejun Wang, Yousif A.2013. Hussin development of an algorithm to generate a Lidarpit-free canopy height model. SilviLaser 2013, October 9-11, 2013 Beijing, China

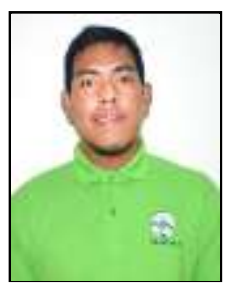

Fejaycris O. Pillodar graduated from the Department of Forestry, College of Forestry and Environmental Studies (2016) of Mindanao State University - Main Campus, Marawi City. He worked as a Science Research Assistant in MSU-IIT Phil-LiDAR 2 Program under Forest Resource Extraction from LiDAR Surveys (FRExLS) component, MSU-IIT, Iligan City, 9200 Philippines.

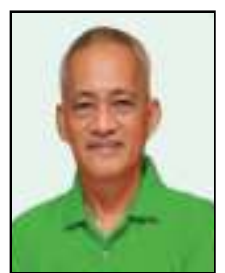

Danilo C. Mero graduated from the Department of Forestry, College of Forestry and Environmental Studies of Mindanao State University - Main Campus, Marawi City. He worked as a Project Staff in FRExLS component, Phil-LiDAR 2 Program, MSU-IIT, Iligan City, 9200 Philippines. He is also a former dean and now a professor in MSU-Main Campus, Marawi City. He specializes in forestry and natural resources.

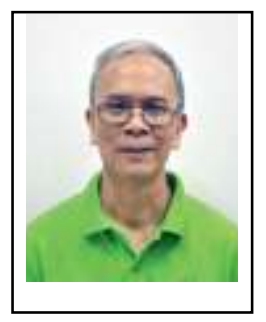

Daniel S. Mostrales graduated his M.S. degree from Asian Institute of Technology in Bangkok. He worked as a Chief Science Research Specialist and as well as a component head of FRExLS and Philippine Hydrologic Datasets (PHD) components in Phil-LiDAR 2 Program, MSU-IIT, Iligan City, 9200 Philippines. He specializes GIS based researches and presented papers to the international conferences.

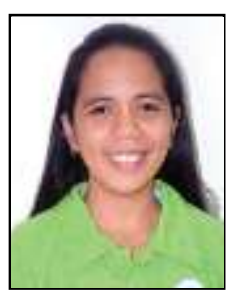

Shara Grace C. Astillero graduated from College of Engineering MSU - IIT, Iligan City. She is currently working as a Senior Research Assistant in MSU-IIT PhilLiDAR 2 Program, MSU-IIT, Iligan City, 9200 Philippines.

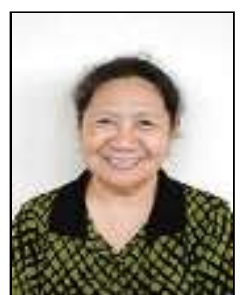

Ma. Teresa T. Ignacio graduated from her M.S. degree in Metallurgical Engineering (1985) from the University of the Philippines. She worked as a professor in the Department of Metallurgical Engineering, MSU-IIT, Iligan City, Philippines. In the field of research, she is working as the project leader of MSU-IIT Phil-LiDAR 2. One of her research based interests are in the field of LiDAR based resource assessment. 